\title{
A tropa e a cidade: a Polícia Militar no Rio de Janeiro durante a abertura e seus impactos negativos futuros para a consolidação de um universo de direitos para as favelas ${ }^{1}$
}

\begin{abstract}
Resumo
Este artigo objetiva analisar a formação e os preceitos embasadores da forma de atuação da Polícia Militar do Rio de Janeiro na virada dos anos 1970 para os anos 1980. Para tanto, parte da perspectiva que esses elementos contribuíram para a criação de estigmas negativos para setores da sociedade e espaços específicos da cidade, sobretudo as favelas e seus moradores, no período abordado, reverberando nos dias de hoje. Como fontes, foram privilegiados a memória de policiais que atuaram nesa época, bem como boletins internos da instituição. Assim, pretendeu-se refletir sobre os significados acerca dos moradores de favelas que podem ser construídos a partir da atuação policial, bem como possíveis consequências relativas a limitações de circulação e alcance de direitos para esse grupo social.
\end{abstract}

Palavras-chave: Abertura Política. Favelas. Polícia Militar.

Cidadania. História. Rio de Janeiro.

\section{Para citar este artigo:}

AMOROSO, Mauro. A tropa e a cidade: a Polícia Militar no Rio de Janeiro durante a abertura e seus impactos negativos futuros para a consolidação de um universo de direitos para as favelas. Tempo e Argumento, Florianópolis, v. 11, n. 27, p. 129 - 157, maio/ago. 2019.

DOI: $10.5965 / 2175180311272019129$

http://dx.doi.org/10.5965/2175180311272019129

\footnotetext{
${ }^{1} \mathrm{O}$ trabalho resulta da pesquisa "Tropa que sobe as favelas: politica de segurança pública e atuação policial como agentes promotores de segregação urbana (1979-2010)", com financiamento da Fundação Carlos Chagas Filho de Amparo à Pesquisa do Estado do Rio de Janeiro (FAPERJ). Gostaria de agradecer a participação dos bolsistas de iniciação científica Júlio César Teixeira e Débora Oliveira, sem os quais este trabalho não teria sido realizado.
} 


\title{
The troop and the city: the Military \\ Police in Rio de Janeiro during the \\ opening and its future negative impacts for the consolidation of a universe of rights for the favelas
}

\begin{abstract}
This article aims to analyze the formation and precepts underlying the way the Rio de Janeiro Military Police operated in the 1970 s to the 1980 s. From this perspective, these elements contributed to the creation of negative stigmas for society and specific spaces of the city, especially the favelas and their inhabitants, during the period covered and reverberated in the present day. As sources, were privileged the memory of police officers who acted at this time, as well as internal bulletins of the institution. Thus, it was intended to reflect on the meanings about the slum dwellers that can be built from the police action, as well as possible consequences on the limitations of movement and the scope of rights for this social group.
\end{abstract}

Keywords: Political Opening. Shanty Towns. Military Police. Citizenship. History. Rio de Janeiro.

Em conhecida conferência, o sociólogo Thomas Humphrey Marshall (1967) elabora uma das principais gêneses do conceito de cidadania a partir das categorias de direitos civis, direitos políticos e direitos sociais. Os primeiros, surgidos no século XVIII, se referem às liberdades individuais, como liberdade de expressão e de ir e vir. Os segundos, nascidos no século XIX, dizem respeito às formas de participação da sociedade na política representativa e institucional. Por sua vez, os terceiros, que datam do século $\mathrm{XX}$, se 
relacionam à segurança e bem-estar de setores da sociedade, visando reduzir ao máximo a desigualdade e diferenças que separam os grupos sociais ${ }^{2}$.

Essa pirâmide desenhada pelo pensador britânico sofreu diversas críticas ao longo do tempo, seja pelos limites temáticos que propõe, seja pela sua inspiração claramente eurocêntrica. Contudo, tal fato não diminui sua contribuição para se pensar como os direitos têm surgido em diferentes momentos históricos de acordo com os desafios das conjunturas sociais, econômicas e políticas que têm se sucedido desde os primórdios da industrialização. Elementos que surgem e se desenvolvem ao longo das chamadas Revoluções Burguesas, as noções de direitos humanos e cidadania passam por transmutações e releituras de acordo com diferentes influências teóricas, atmosferas políticas e contextos espaciais e sociais pelos quais circulam (BOBBIO, 2004, HUNT, 2009). Influenciado pela concepção marshalliana, Jose Murilo de Carvalho (2001) atenta que no caso brasileiro há uma inversão: primeiro, teriam surgido os direitos sociais, principalmente a partir da Era Vargas, seguidos pelos direitos políticos. Os direitos civis, por sua vez, de forma crítica e lamentável, até hoje ainda estariam em processo de consolidação.

Essa última concepção é a principal provocação para este artigo. Afinal, se vivemos em um quadro no qual os direitos básicos como livre expressão, circulação e manutenção da integridade física não são garantidos para todos, temos que relacionar essa realidade restritiva à estruturação da sociedade brasileira que tem a exclusão como uma de suas mais profundas marcas. A mesma sociedade construída nos alicerces da escravidão, do latifúndio e do patriarcalismo, pilares fundamentais para se compreender a nossa desigualdade estrutural histórica. E, se esse arranjo excludente persiste, embora atinja principalmente certos grupos sociais específicos, devemos nos perguntar quais são os agentes sociais que contribuíram para sua perpetuação, sobretudo após a redemocratização e a Constituição de 1988, conhecida como “Constituição Cidadã”.

\footnotetext{
${ }^{2}$ Esse debate, bem como a tipologia de Marshall e a relação e fronteiras entre as três categorias, é de uma complexidade teórica que não se pretende desenvolver nessas linhas iniciais, que possuem uma finalidade meramente introdutória da temática.
} 
De meados para o final dos anos 1970, temos o início da abertura política, que foi um período rico de manifestações culturais e do retorno da mobilização política através de grupos diversos. Entretanto, é preciso se perguntar: como os setores conservadores e desejosos da manutenção da ditadura militar, em seu caráter mais rígido, reagiram aos movimentos progressistas? Até que ponto eles não acabaram fincando bases de resistência própria a fim de manter e, até, propagar sua visão de sociedade e de modus operandi institucional? Essas questões interferiram na prática no caminho para obtenção de direitos por parte de algum setor da sociedade? Desse modo, o objetivo deste artigo é refletir sobre como as bases da atuação da Polícia Militar do Estado do Rio de Janeiro (PMERJ) contribuíram para construir representações e significados ${ }^{3}$ sobre os moradores de favelas durante a abertura política ${ }^{4}$, e como esse quadro colaborou para a construção de uma série de dificuldades, quando não impedimentos, para que essa parcela da sociedade usufruísse de direitos básicos constitucionalmente garantidos até os dias de hoje. Pretende-se, sobretudo, sublinhar que essa situação é um dos exemplos que demonstram um caráter limitador e excludente da cidadania que se pretendeu construir durante a "Nova República", sobretudo por ela ser temporalmente localizada quando se desenhou o quadro de disputas entre interesses e projetos que permearam a gênese de sua concepção.

\footnotetext{
${ }^{3}$ Representações sociais é um conceito tradicional debatido por diferentes áreas de estudos das ciências humanas, tendo sua origem nas Ciências Sociais. Seu surgimento pode ter um paralelo traçado à noção de representações coletivas, de Émile Durkheim (1986), e influencia autores como Serge Moscovici (1978) e Erving Goffman (1988). Trata-se, grosso modo, de um conjunto de ideias e noções originárias do processo de interação social utilizadas como ferramentas de referência a objetos, acontecimentos, indivíduos e grupos sociais.

4 Para o presente artigo foram entrevistados cinco depoentes, de acordo com a metodologia da História Oral (ALBERTI, 2004), sendo três deles policiais militares da reserva, e os dois últimos, lideranças comunitárias de favelas. Além disso, foram igualmente utilizados três depoimentos de ativistas de favelas tomados em pesquisas anteriores. Dos policiais, dois tiveram seus nomes verdadeiros mantidos, por se tratarem de figuras públicas conhecidas, como se verá mais à frente, e outro, por ainda realizar atividades com a PMERJ, mesmo estando na reserva, teve um nome fictício atribuído. O mesmo se dá com as lideranças entrevistadas, para fins de preservação. Conforme a própria metodologia escolhida estabelece (ALBERTI, 2004), também foi feita análise documental de legislação pertinente, bem como de boletins e relatórios Internos da PMERJ do final dos anos 1970.
} 


\section{Considerações iniciais sobre a atuação da PMERJ}

Sobre a atuação policial na cidade do Rio de Janeiro, é possível observar, através da análise da literatura pertinente, como seu aparato possui a forte capacidade de desempenhar o papel de, em conjunto com outras instituições, ordenadora do espaço urbano, produzindo significados diversos, mas comumente referente à noção de classes perigosas, sobre as diferentes áreas da cidade. No século XIX, é visível a preocupação com espaços identificados com a presença de negros, o que revela uma atuação pautada em noções escravocratas, clientelistas e autoritárias (HOLLOWAY, 1997). No início do século XX, por sua vez, nos primórdios do período republicano, nota-se uma certa continuidade com tal tradição, com a atuação de forma a criminalizar certos grupos sociais e seus espaços de frequência, abarcando, além de negros, estrangeiros e prostitutas (BRETAS, 1997a, 1997b). Durante a Era Vargas, principalmente no Estado Novo (1937-1945), a ação policial continua a contribuir para a construção de um imaginário sobre os "inimigos da sociedade", insuflando representações sobre a ideia de classes perigosas, privilegiando elementos como o estrangeiro e, pelo viés ideológico, o “comunista” (CANCELLI, 1994).

Durante a ditadura de 1964, sobre a atuação da Polícia Militar, é possível citar o Decreto-Lei n 337, de 13 de março de 19675, que definia como suas atribuições:

a) executar o policiamento ostensivo, fardado, planejado pelas autoridades policiais competentes, a fim de assegurar o cumprimento da lei e manutenção da ordem pública e o exercício dos poderes constituídos b) atuar de maneira preventiva, como força de dissuasão, em locais ou áreas específicas, onde se presuma ser possível a perturbação da ordem.

Desse modo, observamos que, além de determinar a atuação da Polícia Militar como executora de policiamento ostensivo, ainda que não de sua exclusividade, a ideia de "preventiva" seria referente ao papel de intimidação em locais em que possam estar previstas "perturbações da ordem", indo ao encontro da ideia de uma atuação como

\footnotetext{
${ }_{5}^{5}$ Disponível em: <http://www.planalto.gov.br/ccivil_03/decreto-lei/1965-1988/Del0317.htm>. Acesso em: 09 fev. 2019.
} 
Batalhão de Choque, uma das atribuições dessa instituição policial. O Decreto-Lei $n^{\circ} 667$, de 2 de julho de 1969, determina que a atuação da Polícia Militar deve:

a) executar o policiamento ostensivo, fardado, planejado pelas autoridades policiais competentes, a fim de assegurar o cumprimento da lei, a manutenção da ordem pública e o exercício dos poderes constituídos; b) atuar de maneira preventiva, como força de dissuasão, em locais ou áreas específicas, onde se presuma ser possível a perturbação da ordem.

Assim, além da manutenção do que o governo militar considerava como uma atuação "preventiva", temos uma alteração do artigo que confere a exclusividade do policiamento ostensivo à PMERJ. É interessante notar a data, uma vez que esse DecretoLei é de aproximadamente sete meses depois da promulgação do Ato-Institucional $n^{0} 5$ (13 de dezembro de 1968), documento que simboliza o período de maior recrudescimento do governo militar. Desse modo, tornar uma força auxiliar do Exército, por ele comandada, conforme consta nos dois Decretos-Leis anteriormente citados, como a detentora do monopólio do patrulhamento das ruas é condizente com o período de maior repressão promovido pelos militares, a fim de desarticular os grupos de luta armada e exercer controle sobre quaisquer tipos de resistência ao governo ${ }^{6}$.

No que diz respeito às favelas, sua relação com o aparato policial data desde o surgimento desses espaços, ainda no final do século XIX. Tendo em vista a ilegalidade desse tipo de moradia, confirmada pelo Código de Obras de 1937, o aparato repressivo ligado ao Distrito Federal era o responsável por subir os morros e destruir os barracos feitos a partir de material improvisado (GONÇALVES, 2013). Inclusive, em memórias de antigas lideranças de diversas favelas, é comum a imagem de pessoas construindo moradias improvisadas nos morros da cidade à noite, como forma de evitar essa repressão (PANDOLFI; GRYNSZPAN, 2003). A bem da verdade, as favelas possuem uma relação complexa com o imaginário urbano carioca. Se, por vezes, é possível notar uma certa valorização pelo seu aspecto cultural, nessa mais que secular relação, também se

\footnotetext{
${ }^{6}$ Sobre a repressão à oposição no período ver: GORENDER, 1987, REIS FILHO, 1990, PANDOLFI, 1995, FERREIRA \& REIS FILHO, 2007.
} 
nota uma criminalização de seus moradores, inclusive de suas próprias manifestações culturais (VALLADARES, 2005).

E essa criminalização é possível de ser percebida ainda nos primórdios do século XX, como mostra este trecho de uma reportagem, de 1902, sobre o Morro da Providência: “Lugares existem no Rio de Janeiro onde não aparece sombra de polícia. Um deles é o morro da Providência, onde os celerados de todas as espécies campeiam à vontade, praticando toda a sorte de perversidades" (MATTOS, 2004, p. 36). Esses fatos exemplificam a relação histórica de repressão e tensionamento existente entre os moradores dessas áreas e o efetivo policial ao longo do século XX.

\section{A PMERJ e o contexto da abertura política}

De meados para o final dos anos 1970, temos um momento histórico de ampla mobilização da sociedade brasileira, que se mostrava cada vez mais descrente com o governo militar, uma vez que o modelo econômico, chamado de "milagre brasileiro", mostrava sinais cada vez mais claros de esgotamento7 . Em termos políticos, a sociedade vivia o debate que precedeu a Lei da Anistia $^{8}$, além da renovação da mobilização sindical e popular.

O próprio movimento associativo de favelas deu uma guinada através de uma geração que pregava uma postura mais combativa contra o governo estadual do Rio de Janeiro (DINIZ, 1982, BRUM, 2006). Durante a ditadura de 1964, diversas de suas lideranças mais combativas foram perseguidas politicamente por organizarem a resistência contra o programa de remoção empreendido pelo governo militar. Esse programa, que possuía a meta de erradicar todas as favelas cariocas até 1976, atuou

\footnotetext{
7 A crise econômica perduraria durante os anos 1980 e 1990. Alguns dados são ilustrativos sobre como a crise afetou o estado fluminense, cujo crescimento industrial entre 1970 e 1993, já inclú́dos dados do estado da Guanabara até 1975, foi de 143,1\%, enquanto São Paulo e Minas Gerais os dados foram, respectivamente, de $253,56 \%$ e $405,02 \%$, sendo o total nacional de 300,73\% (OSÓRIO, 2005: 25). No plano nacional, os anos de 1980 e 1981 trouxeram inflação anual de 110,2\% e 95,1\%, respectivamente, sendo que "paralelamente, inaugurou-se o crescimento negativo do PIB real na história brasileira" (CYSNE, 1994: 257).

${ }^{8}$ A Lei no 6.6683 , de 28 de agosto de 1979 , conhecida como Lei da Anistia, foi objeto de amplo debate e mobilização social. Entretanto, possui um certo aspecto conservador, uma vez que colocou ressalvas para a anistia de opositores ao regime militar. Para um debate atualizado sobre as anistias ao longo do século XX, ver: CUNHA, 2010.
} 
principalmente na valorizada zona sul da cidade, entre 1968 e 1975, resultando no desaparecimento de 60 favelas e na remoção de aproximadamente cem mil pessoas (PANDOLFI \& GRYNSZPAN, 2002). Nesse quadro de perseguição, assumem lideranças mais alinhadas com o governo nas esferas estadual e federal, até a guinada anteriormente citada. Mesmo assim, deve ser chamada a atenção de que desde o início do século XX é possível observar a organização de moradores para reivindicações de melhorias e acesso a serviços (GONÇALVES, 2013).

O período de redemocratização que começa a desabrochar possui uma face contraditória. Nesse contexto, é preciso debater o caráter conservador da nossa Lei da Anistia, para se entender os limites da nossa insurgente democracia. Primeiramente, é preciso ter em mente que em nosso período republicano, tivemos 48 anistias, a primeira em 1895, a última em 1979 (CUNHA, 2010). Elas possuem a característica comum de serem pautadas pela categoria de conciliação, de modo a revelar um aspecto conservador da sociedade brasileira, a exemplo do que ocorreu na Proclamação da República, quando se deu um pacto conciliatório para a adoção de ideias liberais, de maneira a se criar um quadro político e social no qual a admissão na vida pública ocorreria a partir da confiança do grupo dominante e de demonstrações de convicções moderadas. Porém, o debate sobre a anistia de 1979 teria ocorrido em uma conjuntura diferenciada pelos distintos embates entre os setores da sociedade civil, e até dentro da corporação militar, que tentaram influenciar o processo que teve como legado a marca do esquecimento, admissibilidade e confiança (CUNHA, 2010).

Igualmente, a partir de meados dos anos 1970, nota-se uma nova configuração da atuação da criminalidade, perceptível principalmente nas grandes capitais brasileiras, como as cidades do Rio de Janeiro, São Paulo e Belo Horizonte. Essa mudança teria em seus aspectos mais perceptíveis o aumento generalizado de roubos e furtos a residências, veículos e transeuntes; o maior grau de organização social do crime; o incremento da violência nas ações criminais; e o aumento das taxas de homicídio. Segundo Kant de Lima, Misse e Miranda (2000, p. 49): “essa mudança de padrão se consolidaria e se expandiria nos anos 1980, com a generalização do tráfico de drogas, especialmente da cocaína, e 
com a substituição de armas convencionais por outras, tecnologicamente sofisticadas, com alto poder de destruição".

Contudo, é importante frisar que o jogo do bicho já chamava atenção sobre o debate relativo à violência urbana, por vezes encampando as favelas, antes da consolidação da figura do traficante de drogas como imagem de associação a esses espaços com a questão da violência e como ameaça à sociabilidade urbana carioca (MISSE, 1997, BURGOS, 1998). Entretanto, por volta de meados dos anos 1970, foram fundadas as falanges Vermelha e do Jacaré, nos presídios de Ilha Grande e Frei Caneca, respectivamente. Voltadas para questões internas dos detentos, posteriormente esses grupos dariam origem ao Comando Vermelho e Terceiro Comando, os mais antigos e principais grupos de traficantes do Rio de Janeiro (MISSE, 1997).

Pela análise das fontes, é interessante notar que a questão do tráfico de drogas, pelo menos em uma análise inicial, ainda não causava grande alarme dentro da própria corporação policial militar no período. Tal afirmativa está baseada na promoção de cursos de formação realizados em 1978. Foram oferecidas diversas modalidades, como curso de motociclistas, aspectos turísticos e culturais da cidade do Rio de Janeiro, manutenção para mecânicos e patrulhamento rodoviário. Dos citados anteriormente, o número de inscritos foi de, respectivamente: $24,29,36$ e 42. No mesmo período, foi realizado um curso de repressão ao tráfico de drogas, que teve apenas três inscritos, ou seja, um número consideravelmente anterior aos outros, principalmente quando se pensa na proporção que a questão tomará nas décadas seguintes (RELATÓRIO GERAL DA PMERJ, 1978). Abaixo, segue o depoimento do subtenente Anselmo, que no final dos anos 1970 era um recém-ingressado na corporação e narra suas memórias de como era a sua rotina de patrulhamento em uma das mais conhecidas favelas do Rio de Janeiro (depoimento do subtenente Anselmo, 18/05/2015 ${ }^{9}$ ):

\footnotetext{
${ }^{9}$ Oficial que serve no $2^{\circ}$ BPM há aproximadamente 30 anos, daí sua escolha como depoente. Anselmo é um nome fictício, escolhido em pré-acordo para a preservação do depoente, uma vez que o mesmo continua atuando no Batalhão. Não foi feita a escolha de omitir os nomes de Paulo Ramos e Jorge da Silva por se trataram de figuras públicas de opiniões conhecidas e que há muito já deram baixa da Polícia Militar. $O$ primeiro construiu longa carreira política como deputado estadual do Rio de Janeiro, passando por partidos como PSOL e PDT. O segundo é professor da Universidade do Estado do Rio de Janeiro (UERJ) e atua desde longa data como consultor no campo da Segurança Pública, possuindo vasta bibliografia sobre
} 
Eu trabalhei na Rocinha quando eu fui recruta, eu rodava aquela Rocinha de madrugada e a nossa arma era o 38, com munição, pra tu ver a diferença, você hoje roda a Rocinha com um 38? Tu vai rodar!

$\mathrm{Na}$ madrugada e tudo, durante a noite ainda, naquelas vielas todas, patrulhava aquilo tudinho, aquele morro, sem problema nenhum.

(sobre a relação com o morador) Era boa, era boa.

Em depoimento sobre sua rotina na favela, o policial dá a entender que o local não oferecia grandes perigos, pois realizava sua ronda com arma de calibre 38 , considerada de baixo poder de fogo. Ele mesmo afirma que seria um quadro diferente dos dias de hoje, nos quais você deveria usar armamento de grande impacto ou "tu vai rodar". Ele ainda afirma ser bom o relacionamento com o morador local ${ }^{10}$.

De fato, esse depoimento não revela uma necessidade de se obter uma formação de confronto armado com quadrilhas em áreas pouco conhecidas e marcadas por vielas e becos, características de muitas favelas. Não quer dizer que não haja outros elementos da formação policial que privilegiem outro tipo de repressão, como será explorado mais à frente. Também devemos ter em mente que essa aparente tranquilidade da rotina do ponto de vista do policial, pode ser uma narrativa romantizada do passado a partir de sua perspectiva e valores pessoais, algo muito comum quando se trata de discursos de memória.

Em um depoimento de um morador da favela do Borel, outra antiga e conhecida comunidade carioca, temos o quadro de uma relação não tão pacífica e amistosa (depoimento de Bruno ${ }^{11}$, 25/10/2011):

o assunto. No entanto, quanto aos policiais que ainda mantêm vínculo com a instituição, mesmo quando deram baixa e atuam através do programa "Tempo Certo", voltado para o uso de policiais da reserva em serviços específicos, preferiu-se a escolha por nomes fictícios, por uma questão de preservação. O mesmo vale para os moradores de favelas entrevistados.

${ }^{10}$ Contudo, é preciso fazer uma nota sobre a estrutura policial naquele momento. Não existiam dados seguros sobre as condições e o aparato da PMERJ como números de soldados por Batalhão, viatura, armamento, quando e onde ocorriam as operações, dentre outros. Os próprios índices sobre a violência no Rio de Janeiro no período eram de origens, muitas vezes, duvidosas. Tais índices ganham maior confiabilidade a partir do debate sobre a questão no início dos anos 1990 com as chacinas da Candelária e de Vigário Geral, ambas em 1993, bem como a mobilização de diversos setores e organizações da sociedade para que o tema seja debatido e conhecido a partir da seriedade que evoca. Esse debate e pesquisas feitas por organizações como o Viva Rio e o Instituto Superior de Estudos da Religião (ISER) acabaram se relacionando com a criação do Instituto de Segurança Pública do Estado do Rio de Janeiro (ISP), principal criador e divulgador de dados sobre o tema, em 1999. Para acompanhar esse debate ao dos anos 1990, ver SOARES, 1996 e 2000.

${ }^{11}$ Liderança da favela do Borel, cujo nome foi trocado para preservação de sua identidade. 
Nessa época (virada dos anos 1970 para 1980) tinha um pessoal que fumava maconha, era assim, fumava maconha e ficava de bobeira no morro. Ficava tudo lerdo e parado. A polícia vinha e todo mundo corria, entendeu, porque se não todo mundo entrava em cana. Vadiagem e todo mundo corria. A polícia corria, nós corríamos pra caramba e não pegava ninguém. Eu corria para o mato, nós corríamos à beça. E ninguém era bandido, mas não podia ficar parado se não a polícia levava.

Esse depoimento já demonstra a existência do tráfico de drogas naquela época, embora não com as tonalidades e engrenagens atuais. Há uma clara identificação de "ninguém era bandido", mesmo com o consumo de uma droga ilícita, o que mostra o quanto a construção de identidade sobre ser "bandido" ou "trabalhador" é de grande complexidade e envolve a existência de práticas diversas e diferentes contextos. Tal definição identitária não pode ser definida por uma única situação, ocorrência ou hábito, daí surgindo sua já mencionada complexidade (ZALUAR, 1994). Contudo, por mais que a memória revele um confronto com a polícia que, nem de perto, beira aos conflitos armados de grande letalidade, ainda assim destoa da memória de absoluta tranquilidade do policial. E essa relação é vista como uma relação entre moradores e poder público, sendo uma forma de abordagem do Estado para esses espaços através de um elemento repressivo, como pode ser observado nesta fala de uma habitante do Morro Santa Marta, outra conhecida e antiga favela carioca (depoimento de Adriana ${ }^{12}$, 12/08/2015):

(sobre a presença ou ausência do Estado nas favelas) O Estado nunca abandonou porque sempre teve polícia. Se sempre teve polícia aqui no Santa Marta, se sempre teve visita dos policiais (...) então tem Estado. A polícia não é do Estado? Então não tem a ausência do Estado, porque sempre teve polícia.

Dentro do quadro descrito acima, cuja influência não deve ser relacionada apenas à criminalidade, mas às suas formas de repressão, que gostaria de compreender a atuação da PMERJ, a partir do final dos anos 1970, e como a polícia constrói uma autoimagem de elemento regulador de condutas e sociabilidade. Primeiramente, é possível encontrar uma memória policial referente à sua atuação como dispositivo

\footnotetext{
${ }^{12}$ Importante liderança local, cujo nome foi trocado para preservação de sua identidade.
} 
regulador da cidade, através de uma ideia própria de manutenção da ordem (depoimento de subtenente Rocha ${ }^{13}$, 18/5/2015):

(perguntado sobre a possível diferença na formação policial para atuação em municípios de diferentes graus de urbanização e número de habitantes) A formação era geral, não tinha diferença, até porque não nos era passada a realidade de outras cidades. A polícia era voltada para a cidade do Rio de Janeiro, os problemas da cidade, dos morros, dos confrontos, as matérias eram voltadas para isso.

Nesse trecho do depoimento, pode-se perceber que a formação recebida por praças e oficiais nos centros de formação da PMERJ, por mais que a mesma sirva o estado do Rio de Janeiro e seus municípios de diferentes dimensões e contingente populacional, é voltada para a atuação na grande metrópole, a capital do estado. A memória do depoente ainda elenca, quase que automaticamente, elementos que determinariam a rotina desse policial em sua prática profissional futura, a exemplo de "morros", o que denota a atuação em favelas, e os "confrontos", o que revela o que se espera, muitas vezes, quando se atua nesses espaços.

Assim, o futuro policial teria uma forma específica de usufruir do espaço urbano, estabelecer trajetos de policiamento, formas de lidar com determinadas áreas, construindo uma trama de significados sobre a cidade a partir da forma como ele se apropria dela, enquanto policial. Os profissionais seriam dotados de um conhecimento técnico de controle de circulação de indivíduos, de repressão e de práticas que resultariam em formas de estigmatização de grupos sociais específicos. A partir desse “saber-fazer", se constituiriam como parte da máquina do Estado, responsável pelo controle da esfera cotidiana das diferentes coletividades que formam a sociedade, dentro da lógica do que Foucault (2000) chama de "biopoder".

Essa forma de ação, que poderia ser considerada a partir da ideia de uma semântica da rotina policial, possui consequências sobre a própria cidade, criando significados para ela que adentram a arena pública de debates, uma vez que, dentro

\footnotetext{
13 Outro oficial que serve no $2^{\circ}$ BPM há mais de 30 anos. Rocha também é um nome fictício, escolhido em pré-acordo para a preservação do depoente, que continua atuando no Batalhão.
} 
dessa perspectiva, o policial é mais um usuário da cidade, e do seu caminhar às suas ações profissionais rotineiras, constrói significados sobre elas (CERTEAU, 2005).

Quando questionado como era a relação entre policiais e moradores de favelas no período, o depoente relata (entrevista com subtenente Rocha, 18/5/2015):

Sempre houve aquela relação de amor e ódio, né, entre o pessoal da comunidade e a polícia. É uma coisa que é interessante é que quando um policial entra numa comunidade, ele entra para cumprir uma missão de garantir a paz e a tranquilidade daqueles moradores, mas quando o policial entra, olhando pela ótica do morador, é o cara que vai arrumar problema, porque se o policial não entra, o traficante não vai dar tiro; se o traficante não der tiro, ninguém da favela, da comunidade é ferido. Quando o policial entra, ele entra levando consigo a troca de tiro, onde o morador fica numa situação difícil. Então, o policial nunca foi bem visto pela comunidade, desde aquela época quando os confrontos eram menos intensos. (grifos meus)

Em sua memória, o depoente aponta o que pode ser visto com uma certa dose de contradição, pois ele caracteriza a atuação da polícia como necessária para a manutenção da ordem, garantindo a "paz e a tranquilidade daqueles moradores". No entanto, ele reconhece que as operações de confronto interferem drasticamente na rotina do morador, uma vez que o "policial entra levando consigo a troca de tiro", o que interfere negativamente na visão dos moradores sobre a ação policial. Interpretação que pode ser vista em depoimentos de moradores de favelas (depoimento de Anderson ${ }^{14}$ 14/07/2015):

E também a lembrança, a imagem de ouvir falar é isso, de que a polícia conhecia quem vivia do tráfico, conhecia os malandros da época, então tinha uma ação muito direcionada. Aí depois um pouco mais, já mais velho, eu lembro da questão da polícia atuando aqui com a questão da vadiagem. Eu lembro da radiopatrulha, aquela preta e branca, aquela joaninha aqui embaixo e eu lembro da polícia parando moradores, e quem não tinha carteira assinada era preso. (...) Eu acho que essa atuação da polícia, ao mesmo tempo que ela sabia quem era quem, essa era um pouco a ideia da época; a polícia sabe quem é malandro e quem não é. Mas, ao mesmo tempo, ela tinha essa atuação indiscriminada, podia parar qualquer um e pedir documento. Eu lembro, eu tenho imagem na minha cabeça daqui na escadaria do morro às vezes você tinha fila de homens sentados e a polícia ali parada, e as mulheres descendo com documento pra liberar cada um ali. Isso tem na minha mente.

\footnotetext{
${ }^{14}$ Liderança política do Morro Santa Marta.
} 
O depoente relata uma incursão policial repressora sobre a Lei da Vadiagem, que data de 1941, que teria ocorrido em meados dos anos 1960. Sua memória caracteriza a ação policial como capaz de saber quem era envolvido com alguma atividade ilícita, mas sua prática acabava abordando todos os moradores. Se contrapusermos a memória de Anderson com a do Subtenente Rocha, vemos a clara tensão entre a polícia e os moradores de favelas. No depoimento do policial, vemos a função de "garantir a paz", mas na fala do morador, essa garantia vinha através da criminalização ampliada e irrestrita.

Diante dos contrastes do depoimento do policial e do morador da favela, é possível nos questionarmos sobre as diferenças de uma memória sobre a violência, principalmente como ela é exercida pelo Estado através do policiamento militar, presente nos dois grupos aos quais pertencem esses indivíduos. Poderíamos falar em uma memória policial da violência, na qual é possível notar a existência de lembranças de ações policiais, sobretudo em favelas, caracterizadas como um saber técnico específico, neutro e pretensamente necessário para a "manutenção da ordem". Essas intervenções, realizadas a partir de uma técnica de atuação, é significada pelos agentes que as executam como benéficas aos moradores desses espaços, ainda que contraditoriamente os prejudique. Do mesmo modo, seria possível falarmos em uma memória da violência policial por parte dos moradores de favelas. Em contraponto à primeira forma de rememoração da ação policial pelos mesmos, seriam marcadas pela negatividade, insegurança e ameaças generalizadas, uma vez que a polícia poderia "parar qualquer um".

Com essa perspectiva, ainda no final dos anos 1970, é possível encontrar memórias de policiais referentes a uma ação anterior à ida com objetivo específico de repressão ao tráfico de entorpecentes, como para conter confusões oriundas de invasões de barracos, ou situações semelhantes, com o uso do Batalhão de Choque, inclusive (depoimento de Sargento Oliveira $\left.{ }^{15}, 14 / 04 / 2015\right)$ :

\footnotetext{
${ }^{15}$ Serviu no Batalhão de Choque entre 1975 e 1977.
} 
Todas as situações, uma situação que pegamos lá na Rocinha, aquelas situações, dava aqueles tumultos lá, aí saia aquele choque duas horas da manhã, naquela época ainda não existia vagabundo, ah não sei o quê, invasão de barraco, aquelas coisas todas, aí ia o choque pra lá,

É possível atentar para uma característica, advinda do militarismo, que acompanha esse profissional desde a sua formação: a necessidade de construção da figura do inimigo. Tal fato pode ser observado na fala de diferentes depoentes

Aqui a nossa formação também é voltada para o inimigo. Só que o nosso inimigo é muito próximo, né, também é o nosso amigo, entendeu (...) você nunca sabe quem é o bandido e quem é o mocinho, entendeu, e as políticas de governo, elas mudam muito... (depoimento de subtenente Rocha, 18/05/2015)

Tinha que ter um inimigo, você trabalha com a mentalidade de que você é um combatente, é um guerreiro, cadê o inimigo? Tem que inventar um inimigo, você tem que inventar um inimigo. Então, por que razão você acha que na cabeça da pessoa, de uma maneira geral, fala assim: "vem cá, o traficante é o problema... não, o usuário é pior... o usuário é pior que o traficante, porque se não fosse o usuário não tinha traficante... então, quem é o inimigo principal? (depoimento de Jorge da Silva, 30/01/2015)

A questão é fundamental para se entender o modo operacional do policiamento ostensivo praticado pela PMERJ. Pela ótica do militarismo, há a necessidade de e inimigo ser exterminado, e o local de atuação deste passa a ser caracterizado como território em disputa. O "inimigo" varia de acordo com a conjuntura histórica e política do período, sendo que, nas últimas décadas, no Rio de Janeiro, o traficante assumiu um papel de centralidade nesse quadro. Mesmo nas palavras de Jorge da Silva, sobre o debate de "quem é culpado pela violência, o traficante ou o usuário", vê-se a guerra às drogas como o estopim. Esse direcionamento poderia ser questionado por alguns vieses, como por que não concentrar esforços na prática para o desvio e venda ilegal de armamento, por exemplo? Desse modo, sob a ótica militar, há um "inimigo" a ser exterminado, assim como um território, seu lócus de atuação, a ser conquistado.

Esse quadro tem gerado consequências, devido à ação do tráfico nas favelas. A atividade criminosa não se restringe a esses espaços, uma vez que envolve uma rede que vai da distribuição ao consumo, passando pela obtenção de armas, além de diversas outras etapas, que englobam o espaço da cidade. Porém, a grande imprensa e setores do 
governo ligado à segurança pública usam a "metáfora da guerra" para significar as favelas como polo irradiador da violência que afeta a sociedade, além de construir representações negativas sobre seus moradores, que vão da conivência ao envolvimento direto, e que criam barreiras para que usufruam de uma série de direitos, inclusive ao da integridade física garantida (LEITE, 2001).

Ainda sobre a questão da criminalização, é possível localizar uma memória específica sobre quais sujeitos sociais foram, e ainda são, configurados como "suspeitos", incorrendo na categoria de alvo de ação repressora:

Paulo Ramos: Houve uma época que a vadiagem era o ilícito, estar sem carteira de trabalho, e tal... então, o policial tinha essa autoridade de discernir. Claro que a discriminação sempre houve. Quer dizer, mesmo no tempo democrático, o pobre, vamos dizer assim, o negro sempre foi... algo que vem desde a escravidão, que vem de um preconceito acentuado. Quer dizer, era privilegiado no sentido de ser o suspeito principal.

Entrevistador: Mas isso chegava a ser verbalizado durante o período de formação?

PR: Não, claro que não. Fazia parte da cultura. Claro que não era verbalizado, porque seria uma atrocidade verbalizar isso, ninguém se atreve, era o óbvio. Quer dizer, o resultado da ação policial demonstrava haver essa orientação, às vezes em conversas paralelas, mas não no curso de formação. (depoimento do Deputado Estadual Paulo Ramos, 29/01/2015)

Jorge da Silva: O suspeito, ele é aquele camarada que mora em determinado lugar, que tem determinada cor e determinada roupa, sempre foi assim...

Entrevistador: Mas isso era mais explícito quando o senhor estava se formando?

JS: Hoje é explícito?

E: Não, mas nem na época era...

JS: O Brasil tem isso, no Brasil dificilmente essas coisas são explicitadas. (depoimento de Jorge da Silva, 30/01/2015)

Como pode ser observado, o negro e o morador de periferias, quando não os dois, trajando determinadas vestes são os sujeitos preferenciais para serem enquadrados na categoria de "suspeitos". Essa caracterização já se daria ainda durante o período de formação, embora nunca tenha sido diretamente verbalizado ou escrito. Mas, como diz Paulo Ramos, “fazia parte da cultura", embora o "resultado da ação policial demonstrasse haver essa orientação”. E não se deve ignorar a própria especificidade da 
questão do racismo na sociedade brasileira, na qual, segundo as palavras de Jorge da Silva, "no Brasil dificilmente essas coisas são explicitadas".

Zizek (2014) chama a atenção para a diferenciação entre dois tipos de violência: sistêmica e subjetiva. A primeira é referente ao controle cotidiano das instituições e às características dos arranjos econômicos e políticos de nossa sociedade. A exemplo das milhares de mortes por causa da fome e da miséria, seria um tipo de violência silenciosa, muitas vezes já internalizada e banalizada pela sociedade, porém capaz de atingir gigantescas proporções. Já o segundo tipo é relacionado à violência por características raciais, de gênero e sexualidade, como casos de feminicídio ou de assassinatos de homossexuais. Casos relativos à intolerância religiosa também poderiam ser incluídos nesse cenário. Nessas situações, haveria possibilidades de surgirem acontecimentos com potencial de chamar a atenção da sociedade, gerando maior comoção. A partir dessa comparação, o filósofo chega a atentar para uma configuração social marcada por um imaginário no qual grupos sociais diversos poderiam se chocar com a tortura de um único indivíduo ao mesmo tempo em que banalizariam a morte de mil pessoas com o apertar de um único botão.

Para a reflexão em curso, creio que as duas categorizações trabalhadas por Zizek podem ser pensadas de maneira cruzada. Afinal, a construção do negro morador de periferias, como as favelas, como "suspeito preferencial" é um dado proveniente do racismo como questão estrutural da sociedade brasileira ${ }^{16}$, caracterizando uma situação de violência sistêmica. Essa característica também é embasada pela banalidade e parcial silêncio sobre a questão em parte considerável de nossa sociedade. E, trata-se de uma configuração histórica da força policial militar que perpassaria sua formação, sua atuação

\footnotetext{
${ }^{16}$ Existe uma vasta e rica bibliografia que aborda questão racial de diferentes formas e olhares disciplinares, que vai da historiografia da escravidão à sociologia da problemática negra nos tempos atuais. Debater esses aportes se trata de um grande, embora valioso e necessário, esforço que ultrapassaria os limites deste artigo. Entretanto, para iluminar o ponto em debate, gostaria de citar alguns dados contemporâneos levantados pela ONG Justiça Global: em 2014, aproximadamente 30 mil jovens foram mortos no Brasil, 80\% eram negros. Entre 2002 e 2012, o número de jovens brancos assassinados caiu 32,3\%, enquanto o de negros aumentou 32,4\%. Disponível em: <http://www.global.org.br/blog/exterminioda-juventude-negra-letalidade-policial-e-violacao-a-vida-no-sistema-socioeducativo-sao-denunciados-aorganizacao-dos-estados-americanos-oea-nesta-sexta-feira-20/> Acesso em: 09 fev. 2019.
} 
e a memória sobre ambas, como pode ser levantada como hipótese a partir do depoimento citado.

Porém, organizações do movimento negro e dos movimentos sociais, bem como do Terceiro Setor, fazem denúncias constantes sobre esses fatos. Desse modo, é possível observar um esforço desses atores em chamar atenção para questões sobre mortes de jovens negros decorrentes de ações policiais, torturas praticadas pelas forças de segurança, dentre outros tristes exemplos possíveis, como forma de sensibilizar a sociedade dentro da categoria de violência subjetiva, tal qual trabalhada por Zizek (2014).

A violência também pode ser entendida como uma tecnologia com implementos e meios próprios que pode ser utilizada para finalidades políticas diversas (ARENDT, 2009). Desse modo, poderíamos entender o uso institucionalizado e histórico dessa tecnologia na formação e ação policial como um indício do caráter sistêmico da violência a essa mesma tecnologia relacionada. Ao mesmo tempo, o seu caráter subjetivo poderia ser pensado pelo fato de a violência se voltar contra uma parcela da sociedade a partir de um recorte de cor, moradia e classe. Poder-se-ia-, assim, considerar a esfera subjetiva da violência, ainda segundo os termos de Zizek (2014), como um campo de onde os sujeitos atingidos podem se reconhecer como vítimas e se aglutinar para resistir ao seu caráter sistêmico.

Desde o final dos anos 1970, quando a abertura política começa a ganhar corpo, vê-se o nascimento do traficante, dentro da lógica já abordada do “inimigo" pela PMERJ, como representação de ameaça associada ao morador de favelas. Tal representação ganha ainda mais força nas décadas de 1980, 1990 e 2000. E, embora, conforme igualmente visto, a questão do tráfico não tivesse tanta repercussão em cursos de formação de policiais, é inegável o impacto que passará a ter nos anos seguintes. Dentro da lógica do policiamento militar, a formação é um fator importante para se entender como seu modelo operacional de execução é construído, bem como seus impactos possíveis.

Faziam parte da grade curricular disciplinas como "armamento e tiro", "técnica policial militar”, “operações de defesa interna e territorial”, “guerra revolucionária”, 
“direito civil”, “direito constitucional”, "psicologia social” e "estudo de problemas brasileiros" (RELATÓRIO GERAL DA PMERJ, 1979, p. 67). As quatro últimas revelam que o policial deveria ter conhecimento básico sobre a legislação da época, recordando que ainda estávamos sob as leis do governo militar, conjuntura que também certamente influenciou o conteúdo programático de "psicologia social” e "estudos dos problemas brasileiros". As três primeiras apenas reforçam o caráter militar da própria Polícia, como diz o nome, Militar.

No entanto, chama a atenção que à medida que o processo de abertura política ganha força, vemos temas como o da "guerra revolucionária". Chama a atenção, mas não causa surpresa, uma vez que nosso processo de abertura foi marcado por disputas dentro do próprio Exército, com a ala ligada à tortura relutante em passar o poder político para a sociedade civil (SKIDMORE, 1988). A própria Lei da Anistia não atingiu as exigências dos seus principais grupos militantes, sendo benéfica aos militares envolvidos com tortura, por exemplo, e não abrangendo todos os presos políticos, algo que só seria estendido em governos seguintes (CUNHA, 2010).

Não é de se estranhar que tais posturas possam ser observadas na própria PMERJ, uma força reserva do Exército à época por ele comandado, não custa lembrar. O curso de “Contraguerrilha urbana”, ministrado entre 1/11/1978 e 31/01/1979 pode ser usado como referência para se refletir sobre a questão. Seu objetivo era "dotar a corporação de elementos altamente especializados e capacitados a participarem de operações especiais de contraguerrilha urbana e rural", sendo que entre seus aptos "não poderão estar respondendo a inquérito civil ou militar, não ter sofrido sanção penal ou militar consideradas incompatíveis com o curso, não ter sofrido qualquer sanção disciplinar grave nos últimos 3 anos" (BOLETIM DA PMERJ, n. 51, 9/8/1978, p. 1666).

Muitos militares, inclusive policiais, foram postos na reserva, ou até sofreram sanções maiores, entre 1964 e 1985, não sendo beneficiados pela Lei da Anistia de 1979 (CUNHA, 2010). Sendo assim, é possível levantar questionamentos que vão além da quebra da hierarquia e do decoro militar, como o fato de se evitar possíveis futuros alunos que estivessem envolvidos em "inquérito civil ou militar, sofrido sanção penal ou militar", principalmente quando se vê o claro elemento discricionário e seletivo que diz 
que essas infrações seriam levadas em consideração caso elas fossem consideradas “incompatíveis com o curso". Outro dado interessante é notar que as aulas seriam coordenadas pelo, à época, Capitão Paulo Amêndola de Souza17 (BOLETIM DA PMERJ, n. 51, 9/8/1978, p. 1666).O atual Coronel Amêndola foi um dos mentores da criação do Batalhão de Operações Especiais da PMERJ (BOPE), em 19 de janeiro de 1978, sob o então nome de Núcleo da Companhia de Operações Especiais (NuCOE) ${ }^{18}$. Em 1981, é preciso registrar, que o comando da Polícia Militar estava entregue ao General Nilton Cerqueira, ligado à ala mais conservadora e favorável à tortura e um dos responsáveis pela Operação Pajussara, conhecida por ter vitimado, em 1971, dentre outros, Carlos Lamarca.

Assim, sendo a virada dos anos 1970 para 1980 um período visto como de abertura política, renovação e reorganização da mobilização associativa, incluindo o movimento de favelas (BRUM, 2006; DINIZ, 1982), é preciso estarmos atentos aos seguintes pontos: a hipótese de um real impacto de uma ala conservadora, incluindo em cursos de formação de soldados e oficiais da PMERJ em sua prática de policiamento ostensivo ${ }^{19}$. Principalmente se pensarmos a ligação dessa ala com a vertente repressora atuante contra a luta armada durante o regime militar, tendo em vista a forte ligação da PMERJ com o Exército. As práticas repressivas influenciadas pelas questões acima foram internalizadas e podem ser observadas na rotina operacional de policiamento ostensivo, conjugando-se com a já abordada caracterização de grupos sociais específicos, e seus espaços de moradia, como "classes perigosas" e "locais perigosos". Não podemos ver como inconsistente a hipótese do quadro ampliado acima afetar negativamente a questão da implementação de direitos pelas décadas seguintes.

Marcelo Burgos (2005) destaca como a cidade deve ser tida como um local de bens e direitos universais. No entanto, a territorialização do espaço urbano, transformando-o em uma região de conflitos de diferentes espécies e grupos, limita a partilha de bens que a democracia tem o potencial de realizar, tornando-se uma causa, e

\footnotetext{
${ }^{17}$ Fez carreira como comentarista de segurança da Rede Record de Televisão e atua como consultor privado na área de segurança pública. Desde 2016, é Secretário Municipal de Ordem Pública do atual prefeito do Rio de Janeiro, Marcelo Crivella.

${ }^{18}$ No Boletim da PMERJ citado, o à época, Capitão Amêndola, é referenciado como pertencente ao NUCDE, embora não haja na fonte a explicitação do significado dessa sigla.

${ }^{19}$ Questionamento semelhante pode ser observado em COIMBRA, 2001.
} 
não consequência, da crise contemporânea nas cidades da América Latina (BURGOS, 2005). Essa territorialização da cidade pode ser relacionada à noção de crítica da intolerância feita por Norberto Bobbio (2004). O filósofo e jurista italiano caracteriza a intolerância como o ato de se achar possuidor da "verdade", adquirindo preconceitos pelo senso comum acrítico por força da tradição, costume e autoridade. Desse modo, a força, e não a persuasão, é utilizada como método de convívio social (BOBBIO, 2004).

Intolerância, segundo a visão de Bobbio, dialoga com a ideia de territorialização da cidade conforme desenvolvida por Burgos. É possível traçar um paralelo entre a força como método de convívio social como um dos pilares para a restrição à partilha de bens por territórios da cidade, no caso do Rio de Janeiro, notadamente, as favelas. E esse uso da força pode ser percebido no modus operandi da PMERJ, da sua formação no período à sua "memória policial da violência”. Nessa última, vemos que a violência pode ser vista como um saber "neutro" para ordenamento de condutas no espaço urbano, ou, nos termos de Hannah Arendt (2009), uma tecnologia para o alcance de fins políticos.

Desse modo, temos um contexto de reconstrução democrática, historicamente localizado, na virada dos anos 1970 para 1980 no qual a própria ideia de democracia tornase um palco de disputa política. Como agravante, em um quadro social no qual não se pode ignorar setores conservadores da sociedade atentando para o perigo de uma pretensa abertura demasiada que retiraria do Estado referenciais de poder que levariam à perda de uma "ordem estabelecida" em uma sociedade cujo imaginário ainda se encontrava refém de um regime ditatorial que, de forma incólume, sem ser punido por seus excessos, conduzia o processo de redemocratização com peso considerável, ainda que não tendo todos os seus anseios atendidos. Mesmo assim, não se deve negar os limites claros por ele colocados à reconstrução de nosso ambiente democrático. Tal situação, de acordo com nossa interpretação, teria sofrido influência considerável de uma ala conservadora da PMERJ inspirada em uma conjuntura operacional formada pela ação repressora contra a luta armada além do próprio ethos militar voltado para a necessária eliminação de um inimigo em potencial. Tendo em vista esse quadro, devemos nos questionar sobre como a ação policial militar de policiamento ostensivo, dentro de um contexto urbano como o do Rio de Janeiro, contribuiu para que a cidade não se tornasse, 
tendo em vista a especificidade do contexto histórico em questão, uma "cidadefortaleza" (DAVIS, 1993) ${ }^{20}$.

Configurações socioespaciais, como essa, constituem um terreno instável para a formulação de pontos sólidos de embasamento para relações profissionais, afetivas, posição social e segurança. Desse modo, a sociedade tenderia a estabelecer foco no que tem certeza de se poder influenciar, como forma de afastar perigos difusos, mas presentes. Esse quadro se aplicaria à indústria da segurança privada, de aulas de defesa pessoal, dentre outros elementos semelhantes. Nota-se, dentro dessa perspectiva, um reforço do medo que alimentaria ainda mais essa considerável indústria de crescentes lucros, envolvendo condomínios fechados, veículos blindados e tantos outros produtos que reforçam o medo que a alimenta (BAUMAN, 2005).

Chega-se, assim, em uma encruzilhada que opõe segurança residencial e comercial contra reforma urbana e integração social, revelando autênticas "cidades-fortaleza" divididas entre "células-fortificadas" e "lugares de terror" onde a "polícia guerreia contra o pobre criminalizado" (DAVIS, 1993, p. 206). Portanto, a percepção social da ameaça, entendida como a gama de representações suscitada pelo medo da violência urbana, apresenta, nessas condições, um potencial mobilizatório maior dos índices e números oficiais sobre a temática propriamente dita, gerando uma certa “cruzada" pela segurança, cujo resultado final é a ameaça ao acesso ao espaço público urbano (DAVIS, 1993).

\footnotetext{
${ }^{20}$ Partindo do caso de Los Angeles, Mike Davis (1993) constrói essa categoria pensando uma arquitetura que isola os bairros das classes populares e áreas de periferia usando-se como um de seus motivos prioritários a "guerra contra as drogas". Desse modo, nota-se a proliferação de novas formas de repressão no espaço urbano, gerando restrições de movimentação dos moradores de bairros operários, embora não apenas. Tal postura apoia-se na resposta armada e no controle de segurança física e arquitetônico das fronteiras espaciais como mote do planejamento urbano, resultando em uma "militarização da vida da cidade" (DAVIS, 1993: 206).
} 


\section{Conclusão}

Desse modo, podemos observar que desde o final dos anos 1970, a PMERJ apresenta uma lógica militarizada presente em sua identidade histórica que influencia não apenas seu modo operacional, mas a forma como ela constrói significados sobre o espaço urbano, sobretudo em áreas de periferia, a exemplo das favelas, quesão vistas como território de disputa contra o inimigo materializado na figura do criminoso. Essa visão, em grande parte, possui respaldo da sociedade, e contribui para que considerável parcela da população passe a ter barreiras, materiais e simbólicas, para ter acesso a um universo de direitos, situação que se configura como um dos maiores desafios a serem suplantados pelo debate brasileiro sobre segurança pública no século XXI.

Historicamente, as favelas são espaços marcados por estigmas negativos apregoados pela sociedade. São espaços mobilizados, no campo do simbólico, como o “outro da cidade”, utilizados como exemplo que não deve fazer parte do espaço urbano (MACHADO DA SILVA, 2002). Deve-se ter em mente que tais representações são construídas por grupos sociais específicos, em um processo do qual os moradores dessas áreas são excluídos da feitura, mas são protagonistas de suas consequências. Tendo em vista o histórico de repressão a esses espaços, que ao longo da maior parte do século XX esteviveram passíveis de sofrer remoções em diferentes formatos por parte do poder público (GONÇALVES, 2013), as instituições policiais já são conhecidas de longa data de seus moradores. Contudo, deve-se ter em mente as especificidades desse convívio e da atuação destas de acordo com cada conjuntura histórica própria.

Em um contexto de abertura política no final da ditadura militar (1964-1985), alguns pontos importantes devem ser sublinhados. Primeiramente, temos, conforme visto na documentação analisada, parte do currículo da Polícia Militar ainda contendo um vocabulário carregado em tons que remetem à Guerra Fria e à repressão à luta armada, já desarticulada no período abordado no Brasil. Com isso, cremos ser possível relacionar essa atuação, norteada pela lógica da guerra e do inimigo, como um forte empecilho à consolidação de diferentes tipos de circulação pelo espaço urbano e de acesso a direitos. Deve ser sublinhado que essa situação ocorre justamente no período de abertura, quando debates sobre construção da democracia e participação cidadã estão em alta. É 
importante ter esse fato em mente para pensarmos justamente a complexidade e polaridade de visões e projetos que resultaram na construção da “Nova República” e de sua "Constituição Cidadã". Devemos nos ater a essa reflexão. tendo em vista certas heranças de condutas, políticas públicas e interpretações sobre os grupos sociais e o papel do Estado sobre eles amplamente autoritárias, que persistiram mesmo após 1985 (PERALVA, 2000). De certa forma, essa situação apresenta chances de reverberar ainda mais em um grupo social tradicionalmente visto como "ameaça" ao universo do formal.

Nos últimos 40 anos, é possível enxergar uma lógica de militarização do espaço urbano na Europa, Estados Unidos e diferentes países da América do Sul (DAVIS, 1993; GRAHAM, 2016; ZIBECHI, 20015), Com isso, observamos que grupos sociais são tratados sob a ótica do inimigo constante, como manda o credo militar, e, um controle espacial e da circulação dos grupos da sociedade é visto cada vez mais como fortalecido. Essa "militarização da vida na cidade", muitas vezes buscando justificativa na chamada "guerra às drogas", contribui enormemente para a significação de espaços da cidade como "lugares de terror", onde a pobreza é combatida de forma militarizada (DAVIS, 1993).

Nesse lugares, reais e dotados de forte carga simbólica negativa, a repressão se torna ainda mais acentuada e brutal, gerando ameaças e riscos diversos para seus habitantes. No caso do Rio de Janeiro e sua Polícia Militar, é interessante notar uma “memória policial da violência” que significa essas práticas, e sua atuação repressora em geral, como uma espécie de saber neutro, técnico e justificado por uma pretensa manutenção da ordem. Ou seja, é preciso refletir sobre e criticar esse tipo de interpretação possível de ser notada nas diretrizes de atuação da PM nas décadas que se seguem à abertura, até os dias atuais. Essa visão, afinal, atuou e ainda atua na forma como a instituição percebe as favelas e instrui seus agentes para nelas atuarem. Sobretudo ao pensarmos sobre como, desde os anos 1980, e com maior profundidade na década de 1990, a figura do narcotraficante é mobilizada por parcelas influentes na sociedade, como os meios de comunicação, como embasadores de políticas de invasão militarizada e repressão violenta sobre as favelas (LEITE, 2001). 
É de fundamental importância que se perceba e compreenda as raízes históricas da abordagem violenta das favelas, bem como sua caracterização como "problema de polícia", ao mesmo tempo em que se deve estar atento às roupagens que ganham em diferentes períodos históricos. No caso aqui discutido, deve-se ter em mente a imensa contradição entre um debate nacional, ampliado de luta por direitos e participação política, e uma situação prática que mostra o embrião de uma forma de combate militarizado às favelas na virada dos anos 1970 para 1980. Desse modo, a partir desse entendimento, devem-se buscar as bases para a crítica e reversão da situação atual e como a "guerra às drogas" afeta esses espaços com resultados brutais e, infelizmente, apoiados por uma parcela longe de não ser considerável da sociedade carioca ${ }^{21}$.

\section{Referências}

AGAMBEN, Giorgio. Estado de exceção. São Paulo: Boitempo, 2004.

ALBERTI, Verena. Ouvir e contar: textos em história oral. Rio de Janeiro: Ed. FGV, 2004.

ALVES, José Cláudio Souza. Dos barões ao extermínio: uma história da violência na Baixada Fluminense. Duque de Caxias, RJ: APPH, CLIO, 2003.

AMOROSO, Mauro. Caminhos do lembrar: a construção e os usos políticos da memória no morro do Borel. Rio de Janeiro: Ponteio, 2015.

\footnotetext{
${ }^{21}$ Em novembro de 2017 foram divulgados dados de intenção de votos para presidenciáveis no Rio de Janeiro. Neles se observa que o candidato Jair Bolsonaro, deputado federal publicamente conhecido por suas posições extremadas e repressoras no campo, dentre outros, da segurança pública é citado espontaneamente por 19, $1 \%$ dos entrevistados, ocupando o primeiro lugar da pesquisa. Conforme https://odia.ig.com.br/rio-de-janeiro/2017-11-05/informe-jair-bolsonaro-lidera-no-rio-na-disputa-pelapresidencia.html, consultado em 09/02/2019. O mesmo deputado, em um evento para empresários em fevereiro de 2018, ao comentar conflitos entre traficantes da favela da Rocinha, disse que a solução seria "metralhar o local", conforme http://ultimosegundo.ig.com.br/politica/2018-02-11/traficantesbolsonaro.html consultado em 01/05/2018. A popularidade do deputado presidenciável em questão revela o quanto parte significativa da sociedade carioca apoia a visão de segurança pública que ele representa. Bolsonaro acabou eleito para presidente com cerca de $55 \%$ dos votos válidos.
} 
AMOROSO, Mauro; GONÇALVES, Rafael; BRUM, Mario. Police, participation et accès aux droits dans des favelas de Rio de Janeiro: une expérience des Unités de police de pacification (UPP). L'Ordinaire des Amériques (ORDA), Paris, v. 2016, 2014.

ARENDT, Hannah. Sobre a violência. Rio de Janeiro: Civilização Brasileira, 2009.

BAUMAN, Zygmunt. Confiança e medo na cidade. Rio de Janeiro: Jorge Zahar Ed., 2005.

BOBBIO, Norberto. A era dos direitos. Rio de Janeiro: Elsevier, 2004.

BRETAS, Marcos. A guerra das ruas: povo e polícia na cidade do Rio de Janeiro. Rio de Janeiro: Arquivo Nacional, 1997a.

BRETAS, Marcos. Ordem na cidade: o cotidiano da autoridade policial no Rio de Janeiro, 1907-1930. Rio de Janeiro: Rocco, 1997b.

BRUM, Mario. "O povo acredita na gente": rupturas e continuidades no movimento comunitário das favelas cariocas nas décadas de 1980 e 1990. Dissertação (Mestrado em História Social). - Universidade Federal Fluminense, Niterói, 2006.

BURGOS, Marcelo. Dos parques proletários ao favela-bairro: as políticas públicas nas favelas do Rio de Janeiro. In: ZALUAR, Alba; ALVITO, Marcos (Orgs.). Um século de favela. Rio de Janeiro: Ed. FGV, 1998.

CANCELLI, Elizabeth. 0 mundo da violência: a polícia na Era Vargas. 2. ed. Brasília: Editora Universidade de Brasília, 1994.

CARVALHO, José Murilo de. Cidadania no Brasil: um longo caminho. Rio de Janeiro: Civilização Brasileira, 2001.

CERTEAU, Michel. A invenção do cotidiano: artes de fazer. 11.ed. Petrópolis: Vozes, 2005.

COIMBRA, Cecília. Operação Rio: o mito das classes perigosas, um estudo sobre a violência urbana, a mídia impressa e os discursos sobre segurança pública. Rio de Janeiro: Oficina do Autor, 2001.

CUNHA, Neiva Vieira da; MELLO, Marco Antônio. Novos conflitos na cidade: a UPP e o processo de urbanização da favela. Dilema: Revista de Estudos de Conflito e Controle Social. Rio de Janeiro, v. 4, 2011.

CUNHA, Paulo Ribeiro da. Militares e anistia no Brasil: um dueto desarmônico. In: TELES, Edson; SAFATLE, Vladimir (Orgs.). O que resta da ditadura: a exceção brasileira. São Paulo: Boitempo, 2010. 
CYSNE, Rubens Penha. A economia brasileira no período militar. In: SOARES, Gláucio Ary Dillon; D’ARAÚJO, Maria Celina (Orgs.). 21 anos de regime militar: balanços e perspectivas. Rio de Janeiro: Ed. FGV, 1994.

DAVIS, Mike. Cidade de quartzo: escavando o futuro em Los Angeles. São Paulo: Scritta Editorial, 1993.

DINIZ, Eli. Voto e máquina política: patronagem e clientelismo no Rio de Janeiro. Rio de Janeiro: Paz e Terra, 1982.

DURKHEIM, Èmile. Sociologia e filosofia. Rio de Janeiro/São Paulo: Forense, 1986.

FERREIRA, Jorge; REIS FILHO, Daniel Aarão (Orgs.). Revolução e democracia (1964-...). Rio de Janeiro: Ed. Civilização Brasileira, 2007. coleção "As esquerdas no Brasil”, v. 3.

FOUCAULT, Michel. Em defesa da sociedade: curso no Collège de France (1975-1976). São Paulo: Martins Fontes, 2000.

GOFFMAN, Erving. Estigma: notas sobre a manipulação da identidade deteriorada. Rio de Janeiro: Editora LTC, 1988.

GONÇALVES, Rafael Soares. Favelas do Rio de Janeiro: História e Direito. Rio de Janeiro: PUC-Rio/Pallas, 2013.

GONÇALVES, Rafael Soares; AMOROSO, Mauro; BRUM, Mario. "A ditadura e suas persistências: favelas e transição política no Rio de Janeiro”. In: STAMPA, Inez; RODRIGUES, Vicente (Orgs). Ditadura e transição democrática no Brasil: o golpe de estado de 1964 e a (re) construção democrática. Rio de Janeiro: Arquivo Nacional, 2016.

GORENDER, Jacob. Combate nas trevas: a esquerda brasileira, das ilusões perdidas à luta armada. 2. ed. São Paulo: Editora Ática, 1987.

HOLLANDA, Cristina Buarque de. Polícia e Direitos Humanos: Política de Segurança Pública no Primeiro Governo Brizola (1983-1986). Rio de Janeiro: Revan, 2005.

HOLLOWAY, Thomas H. Polícia no Rio de Janeiro: repressão e resistência numa cidade do século XIX. Rio de Janeiro: FGV, 1997.

HUNT, Lynn. A invenção dos direitos humanos: uma história. São Paulo: Cia. Das Letras, 2009.

KANT DE LIMA, Roberto, MISSE, Michel; MIRANDA, Ana Paula Mendes de. Violência, criminalidade, segurança pública e justiça criminal no Brasil: uma bibliografia. BIB: Revista Brasileira de Informação Bibliográfica em Ciências Sociais, Rio de Janeiro, n. 50, jan./jun. 2000. 
LEEDS, Anthony; LEEDS, Elizabeth. A sociologia do Brasil urbano. Rio de Janeiro: Jorge Zahar, 1978.

LEITE, Márcia. Para além da metáfora da guerra: percepções sobre cidadania, violência e paz no Grajaú, um bairro carioca. Tese (Doutorado em Sociologia e Antropologia) Universidade Federal do Rio de Janeiro, Rio de Janeiro, 2001.

MACHADO DA SILVA, Luiz Antônio. "A continuidade do "problema da favela". In: OLIVEIRA, Lúcia Lippi (Org.). Cidade: história e desafios. Rio de Janeiro: Ed. FGV, 2002.

MARSHALL, Thomas H. "Cidadania e classe social”. In: Cidadania, classe social e status. Rio de Janeiro: Jorge Zahar, 1967.

MATTOS, Romulo Costa. A “aldeia do mal”: o morro da favela e a construção social das favelas na Primeira República. Dissertação (Mestrado em História) - Universidade Federal Fluminense, Niterói, 2004.

MISSE, Michel. As ligações perigosas: mercado informal ilegal, narcotráfico e violência no Rio de Janeiro. Contemporaneidade e educação, Rio de Janeiro, v. 1, 1997.

MOSCOVICl, Serge. A representação social da psicanálise. Rio de Janeiro: Zahar, 1978.

OSÓRIO, Mauro. Rio nacional, Rio local: mitos e visões da crise carioca e fluminense. Rio de Janeiro: Ed. SENAC, 2005.

PANDOLFI, Dulce. Camaradas e companheiros: memória e história do PCB. Rio de Janeiro: Relume-Dumará/Fundação Roberto Marinho, 1995.

PANDOLFI, Dulce; GRYNSZPAN, Mário. Favelas e poder público: uma relação delicada. In: OLIVEIRA, Lúcia Lippi (Org.). Cidade: história e desafios. Rio de Janeiro: Ed. FGV, 2002.

PANDOLFI, Dulce; GRYNSZPAN, Mario (Orgs.). A favela fala: depoimentos ao CPDOC. Rio de Janeiro: Ed. FGV, 2003.

PERALVA, Angelina. Violência e democracia: o paradoxo brasileiro. São Paulo: Paz e Terra, 2000.

RANCIÈRE, Jacques. Ódio à democracia. São Paulo: Boitempo, 2014.

REIS FILHO, Daniel Aarão. A revolução faltou ao encontro: os comunistas no Brasil. São Paulo: Brasiliense, 1990.

SKIDMORE, Thomas. Brasil: de Castelo a Tancredo, 1964-1985. Rio de Janeiro: Paz e Terra, 1988. 
SOARES, Francisca Vergínio. A politica de segurança pública dos governos Brizola e Moreira Franco à margem da nova violência. Rio de Janeiro: Papel \& Virtual, 2002.

SOARES, Luís Eduardo. Violência e política no Rio de Janeiro. Rio de Janeiro: Topbooks, 1996.

SOARES, Luís Eduardo. Meu casaco de general: 500 dias no front da segurança pública do Rio de Janeiro. São Paulo: Companhia das Letras, 2000.

VALLADARES, Lícia. A invenção da favela: do mito de origem à favela.com. Rio de Janeiro: Ed. FGV, 2005.

ZALUAR, Alba. A máquina e a revolta: as organizações populares e o significado da pobreza. São Paulo: Brasiliense, 1994.

ZIBECHI, Raúl. Territórios em resistência: cartografia política das periferias urbanas latino-americanas. Rio de Janeiro: Consequência, 2015.

ZIZEK, Slavoj. Violência: seis reflexões laterais. São Paulo: Boitempo, 2014.

Recebido em 08/08/2018

Aprovado em 18/03/2019

Universidade do Estado de Santa Catarina - UDESC

Programa de Pós-Graduação em História - PPGH

Revista Tempo e Argumento

Volume 11 - Número 27 - Ano 2019 tempoeargumento@gmail.com 